\title{
CRESCIMENTO DE ÁREA FOLIAR E ÍNDICE DE ÁREA FOLIAR DE MUDAS DE Cordia americana EM DIFERENTES FORMAS DE MANEJO
}

\author{
LEAF AREA GROWTH AND LEAF AREA INDEX OF Cordia Americana \\ SEEDLINGS IN DIFFERENT CROP MANAGEMENT
}

Recebido em 28/09/2017

Jonathan William Trautenmüller ${ }^{1}$

Aceito em 22/11/2017

Juliane Borella ${ }^{2}$

Publicado em 23/11/2017

Myrcia Minatti ${ }^{3}$

DOI: dx.doi.org/10.5380/biofix.v2i2.55508

Sergio Costa Júnior ${ }^{4}$

DOI: dx.doi.org/10.5380/biofix.v2i2.55508

Antônio Pedro Fragoso Woycikievicz ${ }^{5}$

Rafaelo Balbinot ${ }^{6}$

Kauana Engel ${ }^{7}$

\begin{abstract}
Universidade Federal do Paraná, Curitiba, Paraná, Brasil jwtraute@gmaill.com ${ }^{1}$,borella.juli@gmail.com²,myrciaminatti@gmail.com ${ }^{3}$, o.sergio.costa@gmail.com ${ }^{4}$ \& antoniof.w@gmail.com ${ }^{5}$
\end{abstract}

Universidade Federal de Santa Maria, Frederico Westphalen, Rio Grande do Sul, Brasil rafaelo.balbinot@gmail.com ${ }^{6}$ \& kauanaeg@gmail.com ${ }^{7}$

\section{RESUMO}

A área foliar apresenta estreita relação com a interceptação da energia solar. Dessa forma, o objetivo do presente estudo foi avaliar a área foliar e o índice de área foliar em mudas de Cordia americana quando submetidas as diferentes condições de cultivo, de volumes de recipientes (90 e $170 \mathrm{~cm}^{3}$ ) e de densidade de cultivos (50 e 100\% de ocupação da bandeja). O delineamento foi de blocos casualizados em esquema fatorial $5 \times 2 \times 2$, com cinco repetições e 10 plantas avaliadas em cada unidade amostral. Foram realizadas cinco avaliações com intervalos de 20 dias, iniciadas a partir dos 60 dias após a emergência, em que os parâmetros biofísicos avaliados foram à área foliar e o índice de área foliar. Com os resultados, verificou-se que apenas o volume de tubete influencia a área foliar, sendo de $177,3 \mathrm{~cm}^{2}$ para o tubete de $170 \mathrm{~cm}^{3}$ cultivado em densidade de $100 \%$. O índice de área foliar foi influenciado pelo volume do tubete e pela densidade de plantas, em que o maior valor foi de 5,76 para o tubete de $90 \mathrm{~cm}^{3}$ em cultivo com $100 \%$ de densidade. O manejo com adensamento de $100 \%$ influenciou positivamente o crescimento da área e do índice de área foliar.

PALAVRAS-CHAVE: Guajuvira, Manejo de plantas, Volume de recipiente.

\section{ABSTRACT}

The leaf area is closely related to the interception of solar energy. Thus, the aim of this study was to evaluate the area and leaf area index in Cordia americana seedlings when submitted to different growing conditions, container volumes (90 and $170 \mathrm{~cm}^{3}$ ), and crop density (50 and $100 \%$ tray load). The design was randomized blocks in a factorial scheme $5 \times 2 \times 2$, with five replications and 10 plants evaluated in each sample unit. Five evaluations were performed at 20-day intervals starting 60 days after emergence. The biophysical parameters evaluated were leaf area and leaf area index. With the results, it was verified that only the tube volume influences the leaf area, being of $177.3 \mathrm{~cm}^{2}$ for the tube of 170 $\mathrm{cm}^{3}$ cultivated in density of $100 \%$. The leaf area index was influenced by the tube volume and density of plants, where the highest value was 5.76 for the tube of $90 \mathrm{~cm}^{3}$ in culture with $100 \%$ of density. The $100 \%$ density management influenced positively the growth of area and leaf area index.

KEYWORDS: Guajuvira, Plant management, Container volume. 


\section{INTRODUÇÃO}

A espécie Cordia americana (Linnaeus) Gottshling \& J.S. Mill, da família Boraginaceae, apresenta grande importância ecológica e social na região Sul do Brasil. Essa espécie alcança facilmente $25 \mathrm{~m}$ de altura e $80 \mathrm{~cm}$ de diâmetro à altura do peito, podendo ser utilizada para a exploração madeireira. Apresenta preferência por solos profundos e bem drenados, porém é também encontrada em solos rasos (LORENZI, 2016). Adapta-se aos regimes de chuva entre $800 \mathrm{~mm}$ a $2.300 \mathrm{~mm}$ na Argentina e em Santa Catarina, respectivamente. Assim, sua utilização é indicada para recuperação de áreas degradas e áreas de preservação permanente, devido ao seu amplo sistema radicular (CARVALHO, 2004).

Dada a importância ecológica da espécie, a utilização de mudas com qualidade é a chave do sucesso em reflorestamentos para recuperar áreas degradadas e de preservação permanente. Elas devem resistir as condições de campo e produzirem indivíduos com desenvolvimento satisfatório (GONÇALVES et al., 2004). O adensamento de cultivo e o volume de substrato explorado pelas plantas são alguns dos fatores que influenciam na qualidade e na produção de mudas.

O adensamento de plantas estabelece o nível de competição e a capacidade de interceptar a radiação, influenciando diretamente o crescimento e a arquitetura das mudas (CHINCHILLA et al., 1990; CARNEIRO, 1995). Por consequência, afeta a área foliar no dossel das plantas, quanto maior a área foliar, maior será a radiação ativa interceptada e o acúmulo de matéria seca (SANQUETTA et al., 2014).

$O$ conhecimento dos fatores que afetam 0 desenvolvimento das plantas se torna importante, para melhorar as técnicas de viveiricultura. Dessa forma, o presente trabalho teve por objetivo avaliar a área foliar e o índice de área foliar de Cordia americana submetida as diferentes condições de cultivo, de volume de tubete e de densidade de plantas.

\section{MATERIAL E MÉTODOS}

Este trabalho foi instalado e conduzido no campus de Frederico Westphalen - UFSM, localizado no viveiro florestal sob as coordenadas geográficas $27^{\circ} 23^{\prime} 46^{\prime \prime} \mathrm{S}$ e $53^{\circ} 25^{\prime} 38^{\prime \prime} \mathrm{W}$. O ensaio foi montado e conduzido entre os meses de agosto e fevereiro de 2014 e 2015, em ambiente protegido. Segundo a classificação de Köppen, o clima é subtropical úmido ( $\mathrm{Cfb}$ ), com regime de chuvas entre 1.700 e $1.900 \mathrm{~mm}$ distribuídos no ano e temperatura média entre 18 e $20^{\circ} \mathrm{C}$ (ALVARES et al., 2013).

Essa pesquisa foi realizada com Cordia americana, utilizando-se blocos casualizados em esquema fatorial triplo $(5 \times 2 \times 2)$ : cinco datas de avaliação, dois volumes de tubete, duas densidades de plantas na bandeja, com cinco repetições, sendo avaliado as 10 plantas centrais. Os volumes de recipientes utilizados foram 90 e $170 \mathrm{~cm}^{3}$ e as densidades de 50 e $100 \%$ de ocupação da bandeja.

As mudas foram produzidas a partir de sementes adquiridas junto a empresa $\mathrm{MP}^{\circledR}$ sementes. $\mathrm{Na}$ semeadura, foram colocadas quatro sementes por tubete contendo substrato comercial Tecnomax ${ }^{\circledR}$. Foi efetuado raleio das plântulas aos 40 dias após a semeadura, remanescendo somente a mais vigorosa e centralizada. Aos 60 dias após a semeadura, realizaram-se cinco avaliações de área foliar e de índice de área foliar, com intervalos de 20 dias, quando duas mudas por tratamento e repetição foram amostradas.

Após a separação das folhas do caule, foi efetuada a determinação da área foliar total (AF) utilizando um integrador de área foliar (LI 3100, LI-COR, NE, USA). O índice de área foliar (IAF) foi determinado a partir da área foliar total de cada planta e da área explorada por ela, por meio da equação (1).

$\mathrm{IAF}=\mathrm{AF} \times \mathrm{AE}^{-1}$

Em que: $I A F=$ índice de área foliar; $A F=$ área foliar total $\left(\mathrm{m}^{2}\right) ;$ e $A E$ = área explorada pela planta $\left(\mathrm{m}^{2}\right)$.

Os dados obtidos foram submetidos à análise estatística, por meio do software SAS Learning Edition 8.0 (2003). Assim, determinou-se a análise de variância, a análise de regressão e o teste de Tukey a 95\% de probabilidade.

\section{RESULTADOS E DISCUSSÃO}

A análise de variância demostrou a existência de diferença significativa para o crescimento da área foliar (AF) em função dos dias após a emergência (DAE), do tamanho de recipiente e da densidade de cultivo (Tabela 1). Para a $A F$, também houve diferença significativa para as interações tamanho de recipiente com DAE e densidade de plantas.

A AF foi maior aos 140 DAE para o tubete de $170 \mathrm{~cm}^{3}$ com densidade alta de cultivo (Tabela 2). Quando comparado os tamanhos dos recipientes, a partir dos 100 $D A E$, a AF foi maior para o tubete grande, corroborando com os resultados de Antoniazzi et al. (2013) e Abreu et 
al. (2015), com respectivamente Cedrela fissilis Vell. e Enterolobium contortisiliquum (Vell.) Morong.

Tabela 1. Análise de variância para área foliar (AF) e índice de área foliar (IAF) de Cordia americana em função do tamanho de tubete (170 e $90 \mathrm{~cm}^{3}$ ), densidade de mudas (alta e média) e dias após emergência (DAE - 60, 80, 100, 120, 140 dias)

\begin{tabular}{cccc}
\hline \multirow{2}{*}{ Fonte de Variação } & $\begin{array}{c}\text { Graus de } \\
\text { Liberdade }\end{array}$ & \multicolumn{2}{c}{ Quadrado médio } \\
\cline { 3 - 4 } & 4 & $44.965,1^{* *}$ & $27,1^{* *}$ \\
\hline DAE & 1 & $15.899,4^{* *}$ & $10,9^{* *}$ \\
\hline Tubete & 1 & $2.051,3^{* *}$ & $65,8^{* *}$ \\
\hline Densidade & 4 & $1.403,4^{* *}$ & $0,9^{* *}$ \\
\hline DAE $\times$ Tubete & 4 & $344,1^{\text {ns }}$ & $4,1^{* *}$ \\
\hline DAE $\times$ Densidade & 1 & $1.173,7^{*}$ & $0,4^{\text {ns }}$ \\
\hline Tubete $\times$ Densidade & 4 & $155,4^{\text {ns }}$ & $0,2^{\text {ns }}$ \\
\hline DAE $\times$ Tubete $\times$ Densidade & 0,92 & 0,94 \\
\hline Coeficiente de determinação $\left(R^{2}\right)$ & $17,51 \%$ & $18,92 \%$ \\
\hline Coeficiente de variação $(c v \%)$ & $17 \%$
\end{tabular}

** significativo à $99 \%$; ${ }^{*}$ significativo à $95 \%$ de probabilidade; e ns não significativo à $95 \%$ de probabilidade.

Considerando que o aumento da AF propiciou maior aproveitamento da radiação solar para realização da fotossíntese, esse parâmetro morfológico pode ser utilizado para avaliar a produtividade de mudas, tanto em fase de viveiro como em campo (REIS et al., 2013).

Tabela 2. Teste de Tukey para área foliar (AF) de Cordia americana para diferentes dias após a emergência das plântulas (DAE)

\begin{tabular}{|c|c|c|c|c|}
\hline \multirow{3}{*}{ Densidade } & \multicolumn{2}{|c|}{ Área foliar $\left(\mathrm{cm}^{3}\right)$} & \multicolumn{2}{|c|}{ Índice de área foliar } \\
\hline & \multicolumn{4}{|c|}{ Tubete } \\
\hline & Grande & Médio & Grande & Médio \\
\hline \multicolumn{5}{|c|}{$60 \mathrm{DAE}$} \\
\hline Alta & $32,2 \mathrm{aA}$ & 20,6 aA & $0,76 a A$ & $0,89 \mathrm{aA}$ \\
\hline Média & 21,4 aA & 21,1 aA & 0,25 aA & 0,45 aA \\
\hline \multicolumn{5}{|c|}{$80 \mathrm{DAE}$} \\
\hline Alta & $73,1 \mathrm{aA}$ & 53,4 aA & $1,73 \mathrm{aB}$ & $2,32 \mathrm{aA}$ \\
\hline Média & 64,6 aA & 57,8 aA & $0,76 \mathrm{bB}$ & $1,25 \mathrm{bA}$ \\
\hline \multicolumn{5}{|c|}{$100 \mathrm{DAE}$} \\
\hline Alta & $115,7 \mathrm{aA}$ & $91,8 \mathrm{aB}$ & $2,74 \mathrm{aB}$ & 4,00 aA \\
\hline Média & 110,4 aA & $83,4 \mathrm{aB}$ & $1,31 \mathrm{bA}$ & $1,81 \mathrm{bA}$ \\
\hline \multicolumn{5}{|c|}{$120 \mathrm{DAE}$} \\
\hline Alta & $154,2 \mathrm{aA}$ & $93,5 \mathrm{aB}$ & $3,65 \mathrm{aA}$ & 4,06 aA \\
\hline Média & $134,4 \mathrm{bA}$ & $97,6 \mathrm{aB}$ & $1,59 \mathrm{bB}$ & $2,12 \mathrm{bA}$ \\
\hline \multicolumn{5}{|c|}{$140 \mathrm{DAE}$} \\
\hline Alta & $177,3 \mathrm{aA}$ & $142,0 \mathrm{aB}$ & $4,20 \mathrm{aB}$ & 5,76 aA \\
\hline Média & $132,7 \mathrm{bA}$ & $121,2 \mathrm{bA}$ & $1,68 \mathrm{bB}$ & $2,63 \mathrm{bA}$ \\
\hline
\end{tabular}

Médias seguidas por letras distintas na linha (maiúsculas) e na coluna (minúsculas) diferem entre si pelo teste de Tukey à $95 \%$ de probabilidade.

Para os autores Van Volkenburgh (1999) e Nascimento et al. (2011), a AF apresenta função importante na determinação da quantidade de luz que a muda intercepta, na fixação de carbono e na perda de água. Assim, a interceptação da luz, a fotossíntese e as trocas gasosas são diretamente relacionadas com a $\mathrm{AF}$ (LARCHER, 2006).

$A$ análise de variância revelou diferenças significativas para o IAF em função de DAE, densidade, tamanho de recipiente e nas interações DAE com volume de tubete e adensamento das plantas (Tabela 1). Assim, o IAF foi maior aos $140 \operatorname{DAE}(5,76)$ com tubete médio e densidade alta (Tabela 1), porém, o tratamento com a combinação de tubete médio com densidade alta (TMDA) apresentou os maiores valores independente do período de cultivo.

Os maiores IAF na maior densidade de cultivo ocorreram devido a ocupação mais rápida da área foliar sobre os espaços entre as plantas. Dessa forma, em densidades maiores, o IAF se eleva mais rapidamente (SANQUETTA et al., 2014). Esses resultados foram semelhantes aos encontrados por Sanquetta et al. (2014) para Eucalyptus dunnii Maiden.

Os maiores IAF encontrados no presente estudo estão relacionados com as maiores densidades, permitindo que a plante aumente a interceptação da radiação solar, resultando em maior acúmulo de biomassa. A eficiência na interceptação de radiação fotossintética está relacionada com o IAF da cultura, cujo aumento do IAF proporciona elevação na interceptação de radiação (SANQUETTA et al., 2014). Reis et al. (2013) mencionam que a $A F$ e o IAF são os parâmetros biofísicos que determinam a produtividade das culturas.

A área e o índice de área foliar se mantiveram crescentes por todo o período do experimento (Figura 1). Tal efeito era esperado, pois se trata de uma espécie nativa de crescimento moderado a lento (TRAUTENMÜLLER et al., 2014). Sanquetta et al. (2014), estudando mudas da espécie Eucalyptus dunnii, encontraram os maiores IAF e AF aos $150 \mathrm{DAE}$, pois o crescimento e a expansão da área foliar aumenta a interceptação das folhas superiores, o que provoca auto sombreamento e estabilização ou redução do crescimento.

Para produzir mudas de Cordia americana com maior qualidade, deve-se utilizar a densidade alta e tubetes grandes $\left(190 \mathrm{~cm}^{3}\right)$. Eloy et al. (2013) e Sanquetta et al. (2014), ao estudarem respectivamente as espécies Eucalyptus grandis W. Mill ex Maiden e Eucalyptus dunii, concluíram que as densidades maiores proporcionam mudas de melhor qualidade. Isso se deve a maior eficiência de conversão da energia solar em biomassa pelas plantas cultivadas em alta densidade dentro de ambiente protegido (SANQUETTA et al., 2014). 
(A) Tubete grande

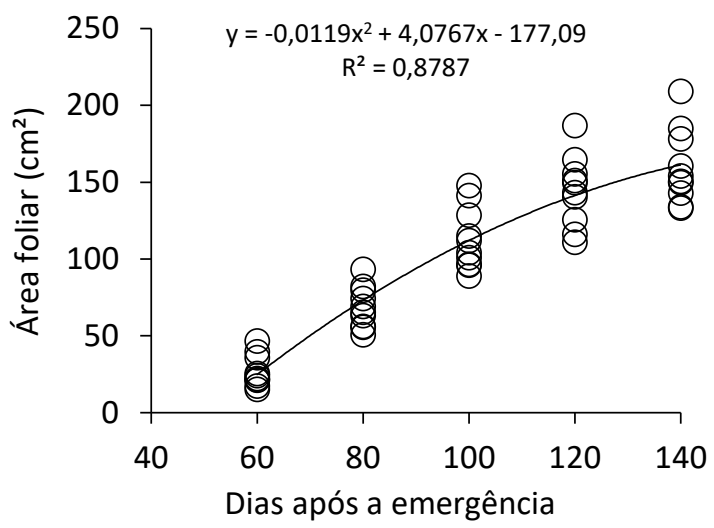

(C) TGDA

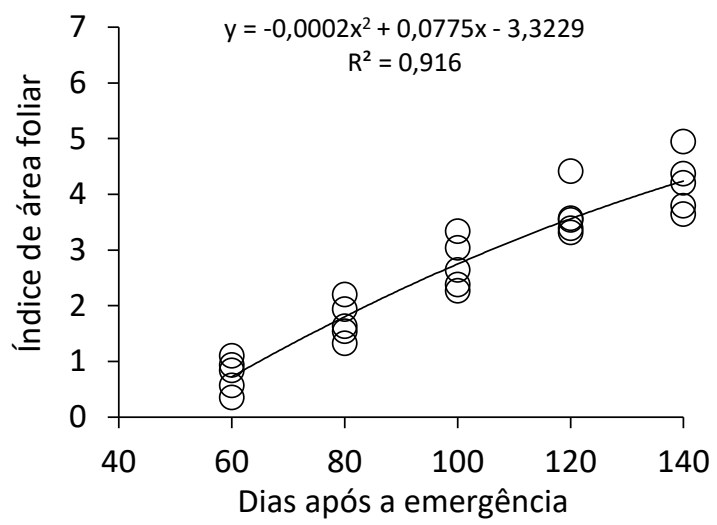

(E) TMDA

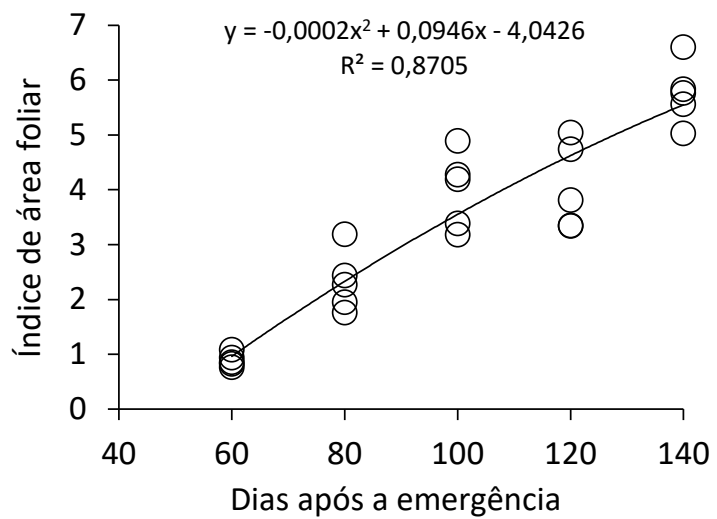

(B) Tubete médio

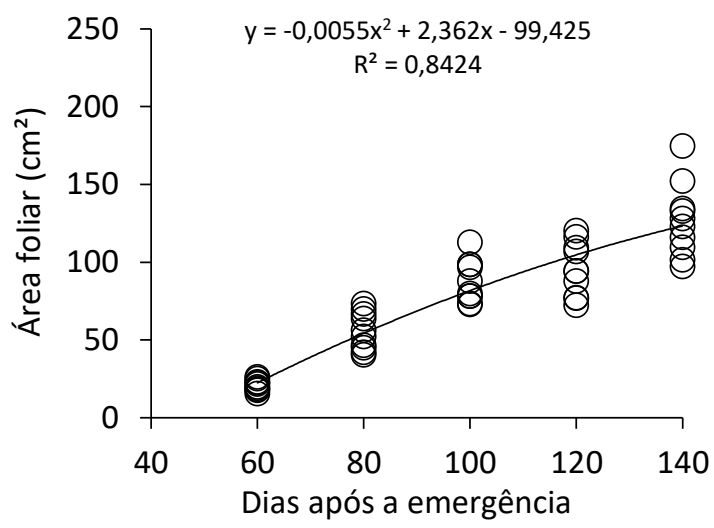

(D) TGDM

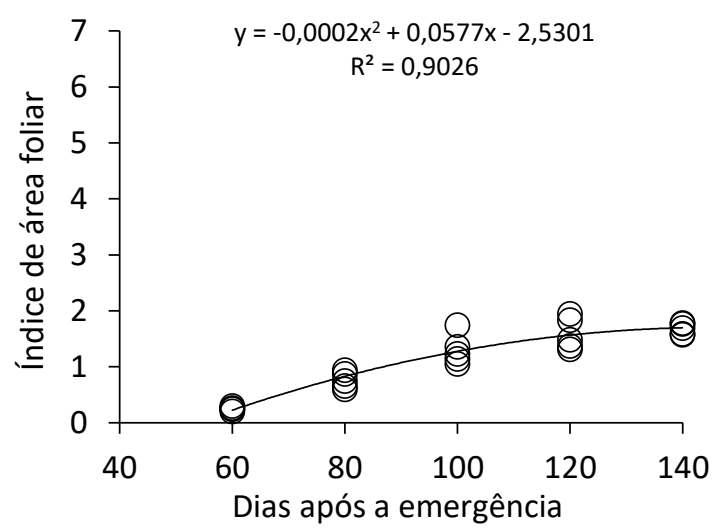

(F) TMDM

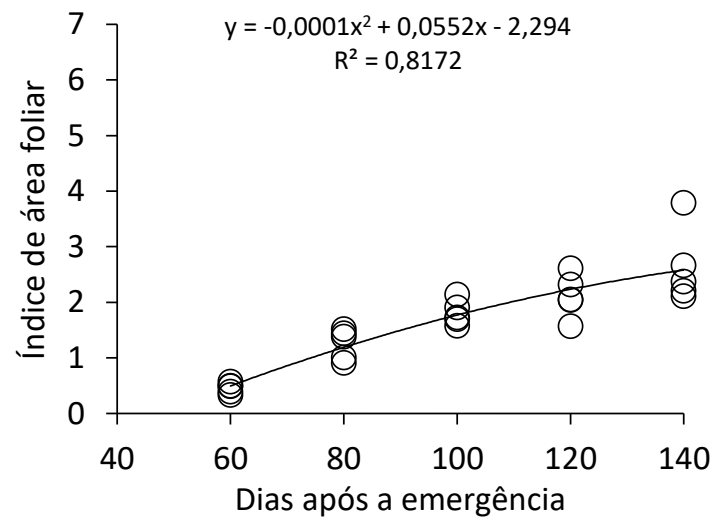

Figura 1. Crescimento em área foliar e índice de área foliar em função dos dias após a emergência de mudas de Cordia americana em diferentes condições de cultivo. TGDA = volume de $170 \mathrm{~cm}^{3}$ e adensamento de $100 \%$; TGDM = volume de $170 \mathrm{~cm}^{3}$ e adensamento de 50\%; TMDA = volume de $90 \mathrm{~cm}^{3}$ e adensamento de $100 \%$; e TMDM = volume de $90 \mathrm{~cm}^{3}$ e adensamento de $50 \%$.

\section{CONCLUSÕES}

O adensamento de $100 \%$ influencia positivamente o crescimento da área foliar e o índice de área foliar, enquanto recipientes de $170 \mathrm{~cm}^{3}$ de tamanho proporcionam maior área foliar. Para o índice de área foliar, o volume de $90 \mathrm{~cm}^{3}$ acarreta em maior incremento.

\section{REFERÊNCIAS}

ABREU, A. H. M.; LELES, P. S. S; MELO, L. A.; FERREIRA, D. H. A. A.; MONTEIRO, F. A. S. Produção de mudas e crescimento inicial em campo de Enterolobium contortisiliquum produzidas em diferentes recipientes. Floresta, v. 45, n. 1, p. 141-150, 2015.

ALVARES, C. A.; STAPE, J. L.; SENTELHAS, P. C.; GONÇALVES, J. L. M.; SPAROVEK, G. Köppen's climate classification map for Brazil. Meteorologische Zeitschrift, v. 22, n. 6, p. 711-728, 2013. 
ANTONIAZZI, A. P.; BINOTTO, B.; NEUMANN, G. M.; SAUSEN, T. L.; BUDKE, J. C. Eficiência de recipientes no desenvolvimento de mudas de Cedrela fissilis Vell. (Meliaceae). Revista brasileira de Biociências, v. 11, n. 3, p. 313-317, 2013.

CARNEIRO, J. G. A. Produção e controle de qualidade de mudas florestais. Curitiba: UFPR/FUPEF, 1995. $451 \mathrm{p}$.

CARVALHO, P. E. R. Guajuvira - Patagonula americana. Colombo: Embrapa Florestas, 2004. 10 p. (Circular Técnica, 97).

CHINCHILLA, C. M.; UMAÑA, C. H.; RICHARDSON, D. L. Material de desarrollo avanzado en viveiros de palma aceitera (Elaeis guineensis Jacq.) - espaciamineto y volumen de bolsa. Turrialba, v. 40, n. 4, p. $428-439,1990$.

ELOY, E.; CARON, B. O.; SCHMIDT, D.; BEHLING, A.; SCHWERS, L.; ELLI, E. F. Avaliação da qualidade de mudas de Eucalyptus grandis utilizando parâmetros morfológicos. Floresta, v. 43, n. 3, p. 373-384, 2013.

GONÇALVES, J. L. M.; STAPE, J. L.; BENEDETTI, V.; FESSEL, V. A. G.; GAVA, J. L. Evaluation of minimum and intensive soil preparation regarding fertility and tree nutrition. In: GONÇALVES, J. L. M.; BENEDETTI, V. Forest nutrition and fertilization. Piracicaba: IPEF. 2004. p. 13-64.

LARCHER, W. Ecofisiologia vegetal. São Carlos: Rima, 2006. $531 \mathrm{p}$.

LORENZI, H. Árvores brasileiras: manual de identificação e cultivo de plantas arbóreas nativas do Brasil. 7. ed. Nova Odessa: Editora Plantarum, v. 1, 2016. 384 p.

NASCIMENTO, H. H. C.; NOGUEIRA, R. J. M. C.; SILVA, E. C.; SILVA, M. A. Análise do crescimento de mudas de jatobá (Hymenaea courbaril L.) em diferentes níveis de água no solo. Revista Árvore, v. 35, n. 3, p.617-626, 2011.

REIS, L. S.; AZEVEDO, C. A. V.; ALBUQUeRQUE, A. W.; JUNIOR, J. F. S. Índice de área foliar e produtividade do tomate sob condições de ambiente protegido. Revista Brasileira de Engenharia Agrícola e Ambiental, v. 17, n. 4, p. 386-391, 2013.

SANQUETTA, C. R.; DALLA CORTE, A. P.; BEHLING, A.; CARDORI, G. C.; COSTA JUNIOR, S.; RUZA, M. S. Crescimento de área e índice de área foliar de mudas de Eucalyptus dunii Maiden. em diferentes condições de cultivos. Revista Biociências, v. 20, n. 2, p. 82-89, 2014.

SAS LEARNING EDITION. Getting started with the SAS learning edition. Cary: SAS PUBLISHING, 2003. 200 p.

TRAUTENMÜLLER, J. W.; BALBINOT, R.; BORELLA, J.; TREVISAN, R.; BALESTRIN, D.; VENDRUSCOLO, R. SABADINI, A. M. Variação longitudinal da massa específica básica da madeira de Cordia americana e Alchornea triplinervia. Ciência Rural, v. 44, n. 5, p. 817-821, 2014.

VAN VOLKENBURGH, E. Leaf expansion - an integrating plant behavior. Plant, Cell \& Environment, v. 22, n. 12, p. 1463-1473, 1999. 